\title{
Aerosol Deposition and Behavior on Leaves in Cool-temperate Deciduous Forests. Part 3: Estimation of Fog Deposition onto Cool-temperate Deciduous Forest by the Inferential Method
}

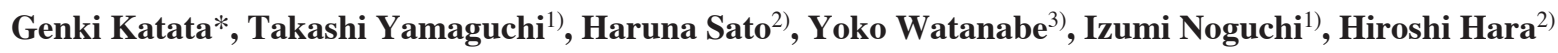 \\ and Haruyasu Nagai
}

Research Group for Environmental Science, Japan Atomic Energy Agency, Ibaraki 319-1195, Japan

${ }^{1)}$ Environmental Conservation Division, Hokkaido Research Organization, Sapporo 060-0819, Japan

${ }^{2)}$ Field Science Center, Tokyo University of Agriculture and Technology, Tokyo 183-8538, Japan

${ }^{3)}$ Field Science Center for Northern Biosphere, Hokkaido University, Sapporo 060-0809, Japan

*Corresponding author. Tel: +81-29-282-5171, Fax: +81-29-282-5857, E-mail: katata.genki@jaea.go.jp

\begin{abstract}
Fog deposition onto the cool-temperate deciduous forest around Lake Mashu in northern Japan was estimated by the inferential method using the parameterizations of deposition velocity and liquid water content of fog (LWC). Two parameterizations of fog deposition velocity derived from field experiments in Europe and numerical simulations using a detailed multi-layer atmosphere-vegetation-soil model were tested. The empirical function between horizontal visibility (VIS) and LWC was applied to produce hourIy LWC as an input data for the inferential method. Weekly mean LWC computed from VIS had a good correlation with LWC sampled by an active string-fog collector. By considering the enhancement of fog deposition due to the edge effect, fog deposition calculated by the inferential method using two parameterizations of deposition velocity agreed with that computed from throughfall data. The results indicated that the inferential method using the current parameterizations of deposition velocity and LWC can provide a rough estimation of water input due to fog deposition onto cool-temperature deciduous forests. Limitations of current parameterizations of deposition velocity related to wind speed, evaporation loss of rain and fog droplets intercepted by tree canopies, and leaf area index were discussed.
\end{abstract}

Keywords: Fog deposition, Inferential method, Parameterization, Visibility, Liquid water content, Deposition velocity, Deciduous forest, Leaf area index

\section{INTRODUCTION}

Acid deposition of pollutants such as sulfur and nitrogen compounds led to a serious atmospheric pollution in aquatic environments and terrestrial ecosystems as a result of rapid economic growth in East Asia. In general, the processes of acid deposition are well known as dry, wet, and fog (cloud water) deposition (Seinfeld and Pandis, 2006). Although monitoring of wet and dry deposition fluxes in East Asia has been implemented since 2001 by the Acid Deposition Monitoring Network in East Asia (EANET), information on fog deposition is currently lacking. Since fog water has high concentrations of solutes, fog deposition significantly contributes to hydrological, nutrient, and pollutant inputs especially in mountainous regions where fog is frequently observed (Lange et al., 2003; Igawa et al., 2002; Herckes et al., 2002). Thus, with air pollution monitoring networks in other countries, such as the Clean Air Status and Trends Network (CASTNET), quantification of fog deposition in forest areas is an important task for assessing acid deposition in East Asia.

Various approaches have been applied to quantify the fog deposition through direct measurements by canopy throughfall and stemflow method (e.g., Mueller et al., 1991), fog collector resembling the natural surfaces (e.g., Lovett, 1984), and lysimeter (e.g., Fowler et al., 1990) etc. However, lacking spatial or temporal representativeness and re-evaporation of deposited fog water before observations can cause errors in these approaches. The eddy covariance method (e.g., Beswick et al., 1991) is also one of the approaches to 
quantify fog deposition with averaging over the footprint area, but it has technical difficulties in the management and needs fast-response instruments which are relatively expensive. The low-cost monitoring approach such as inferential method (Erisman et al., 1994; Hicks et al., 1987) is therefore required to estimate fog deposition flux over terrestrial surfaces.

The inferential method calculates the fog deposition flux as a product of fog deposition velocity and liquid water content of fog (LWC) at the ground level. According to the framework which is based on the analogy of a resistance network, dry deposition velocity is represented as a function of meteorological variables and land surface characteristics (e.g., Zhang et al., 2001; Wesely, 1989). In similarity with dry deposition, some parameterizations of fog deposition velocity have been proposed based on field and numerical experiments in European forests (Katata et al., 2008; Vermeulen et al., 1997). However, the validation studies for the above parameterizations are still very limited in East Asia (e.g., Katata et al., 2011). With regard to LWC, routine measurements are not usually performed in many places except for some mountain sites (Watanabe et al., 2010; Aikawa et al., 2007; Tago et al., 2006; Igawa et al., 2002). Instead of LWC, horizontal visibility (VIS), which represents the intensity of fog and has a good correlation with LWC, is monitored at many surface meteorological and road weather stations. Although empirical relationships for computing LWC from VIS have been proposed for the purpose of fog forecasting and nowcasting (e.g., Stoelinga and Werner, 1999; Kunkel, 1984), studies to evaluate their accuracy are still limited (Eugster et al., 2006; Klemm et al., 2005). Thus, performance tests of the parameterizations for deposition velocity and LWC are required for monitoring of fog deposition in East Asia.

In the present paper, fog deposition onto a cool-temperate deciduous forest in Japan is estimated using the current parameterizations for LWC and fog deposition velocity. The LWC is calculated using the power-law relationship between VIS and LWC proposed by Kunkel (1984) and Stoelinga and Werner (1999). Using the estimated values of LWC and the deposition velocity parameterized in European forests (Katata et al., 2008; Vermeulen et al., 1997), fog deposition flux was calculated by the inferential method. The estimated LWC and fog deposition flux are compared with observational data of weekly LWC and throughfall under the tree canopies, respectively. The performance and limitations of the current parameterizations for LWC and fog deposition velocity are investigated based on the comparison between observed and estimated results.

\section{MATERIALS AND METHODS}

\section{1 Parameterizations for Fog Deposition Estimation}

According to the inferential technique (Erisman et al., 1994; Hicks et al., 1987), the fog deposition flux $\left(F\left[\mathrm{~kg} \mathrm{~m}^{-2} \mathrm{~s}^{-1}\right]\right)$ is represented as a product of the deposition velocity $\left(V_{d}\left[\mathrm{~m} \mathrm{~s}^{-1}\right]\right)$ and $\operatorname{LWC}\left[\mathrm{kg} \mathrm{m}^{-3}\right]$ and is determined as follows:

$$
F=\mathrm{LWC} \cdot V_{d} \text {, }
$$

where the downward flux is positive for $F$. To estimate LWC, the following empirical power-law expression between VIS and LWC is adopted (Stoelinga and Werner, 1999; Kunkel, 1984):

$$
\mathrm{LWC}=\left(\frac{a}{\mathrm{VIS}}\right)^{\frac{1}{\mathrm{~b}}},
$$

where $a$ and $b$ are the empirical parameters determined from the field experiments. Stoelinga and Werner (1999) suggest the values of $a$ and $b$ as 0.027 and 0.88 , respectively. Although Eq.(2) has a larger error in LWC estimation as compared to a newer parameterization as a function of both LWC and droplet number concentration (Gultepe et al., 2006), Eq.(2) still has an advantage that it needs only one parameter, VIS, which is routinely observed at surface meteorological and road weather stations.

To calculate fog deposition flux by the inferential method, it is necessary to use the parameterization of fog deposition velocity, $V_{d}$. Vermeulen et al. (1997) proposed the parameterization of deposition velocity determined from eddy covariance measurements of fog water flux in a coniferous forest in the Netherlands:

$$
V_{d}=0.195 u^{* 2},
$$

where $u^{*}\left[\mathrm{~m} \mathrm{~s}^{-1}\right]$ is the friction velocity over the tree canopy, which is generally obtained by the following equation (Erisman and Draaijers, 1995):

$$
u^{*}=\kappa U_{z}\left[\ln \frac{z-d}{z_{0}}-\Psi_{m}\left(\frac{z-d}{L}\right)+\Psi_{m}\left(\frac{z_{0}}{L}\right)\right]^{-1},
$$

where $\kappa$ is the von Karman constant $(0.4), z[\mathrm{~m}]$ the reference height, $d[\mathrm{~m}]$ the displacement height $(0.7 \times$ $h ; h[\mathrm{~m}]$ is the canopy height), $U_{z}$ the horizontal wind velocity at height of $z, z_{0}[\mathrm{~m}]$ the roughness length, $L$ [m] the Monin-Obukhov length, and $\Psi_{m}$ the stability correction function for momentum. Typical values of $z$ and $z_{0}$ for forest are 20 and $1 \mathrm{~m}$, respectively (Matsuda et al., 2006). $L$ is calculated from solar radiation and cloud cover based on Pasquill stability categories (Matsuda et al., 2006). Thus, Eq.(3) is available with one parameter of friction velocity $\left(u^{*}\right)$, which can be 
calculated from routine meteorological data only (i.e., wind speed, solar radiation, and cloud cover).

The authors have proposed another formulation of deposition velocity (Katata et al., 2008) based on numerical simulation using the one-dimensional multilayer atmosphere-soil-vegetation model (SOLVEG) in a coniferous forest in Germany. The equation is represented as a function of the horizontal wind speed over the canopy $\left(U_{z}\right)$, the leaf area index (LAI), and the canopy height $(h)$ :

$$
\begin{aligned}
& V_{d}=A U_{z}, \\
& A=0.0164(\mathrm{LAI} / h)^{-0.5},
\end{aligned}
$$

where $A$ [non-dimensional] is the slope of $V_{d}$ that depends on vegetation characteristics. Through Eq.(6), the calculations of $A$ agreed with observations in various cloud forests with $\mathrm{LAI} / h>0.2$ (Katata et al., 2008). Since the forest in the study site is sparse as $\mathrm{LAI} / h \simeq$ 0.15 (see subsection 2.2 ), the value (0.04) was directly obtained from the curve of $A$ when $h=10 \mathrm{~m}$ (Fig. 11a in Katata et al., 2008). Eq.(5) has the advantage of considering not only meteorological data but also vegetation parameters (LAI) compared to Eq.(3).

Fig. 1 shows the comparison of fog deposition velocity estimated by two parameterizations at the study site from 10 August to 15 October 2010 (see subsection 2. 2). Using the parameterization of Katata et al. (2008), deposition velocity linearly increases with wind speed as represented by Eq.(5). In contrast, Vermeulen $e t$ al. (1997) shows that the function of deposition velocity

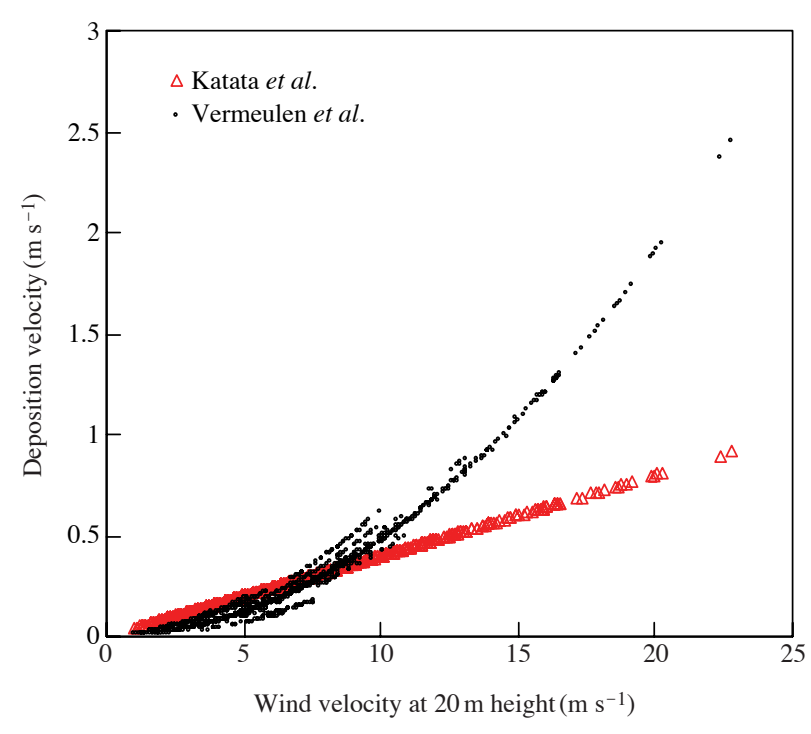

Fig. 1. The relationship between horizontal wind speed at 20 $\mathrm{m}$ height $\left(U_{z}\right)$ and fog deposition velocity $\left(V_{d}\right)$ using two parameterizations of Katata et al. (2008) (open triangles) and Vermeulen et al. (1997) (dots). is proportional to the square of wind speed and represented by Eq.(3), and produces a large value compared with Katata et al. (2008), when $U_{z}>5 \mathrm{~m} \mathrm{~s}^{-1}$. However, such a high wind speed could not be considered while applying Eq.(3) because this equation was validated in the range of $U_{z}$ from 0 to $3 \mathrm{~m} \mathrm{~s}^{-1}$ (Vermeulen et al., 1997). Eq.(5) was parameterized in the range of $U_{z}$ from 0 to $8 \mathrm{~m} \mathrm{~s}^{-1}$ (Katata et al., 2008) indicating a wide availability for estimation of fog deposition under strong high-wind conditions. The impact of wind speed on fog deposition flux is discussed in subsection 3.2.

\section{2 Site Description and Observational Variables}

The study area is characterized as a cool-temperate forest on the somma of a crater lake, Lake Mashu, in Hokkaido in northern Japan (Yamaguchi et al., 2013, the companion paper). The dominant plant species is a deciduous broad-leaved tree, Betula ermanii Cham. (Fujinuma et al., 2004). The authors focused on fog and throughfall events occurring in the study area from 10 August to 15 October 2010. Hourly meteorological data of VIS and horizontal wind speed at $1.5 \mathrm{~m}$ height were observed at the road weather station and were used for calculations of LWC and friction and deposition velocities by Eqs.(2), (4), and (5), respectively. Wind speed at the reference height $\left(U_{z}\right)$ in Eqs.(4) and (5) was derived from that observed at $1.5 \mathrm{~m}$ in height by assuming a logarithmic profile of wind speed in the surface boundary layer. To compute the atmospheric stability $(L)$ in Eq.(4), the hourly data of solar radiation and cloud cover observed at the nearest surface weather stations of Nemuro and Kushiro, respectively, were used. Weekly mean LWC of fog water sampled by an active string-fog collector (Daisho Engineering Co. Ltd., FSK-01) placed at the $1.2 \mathrm{~m}$ above the roof terrace of observation deck was compared with that calculated using Eq.(2). The data of throughfall from three tree stands (plots $\mathrm{A}, \mathrm{B}$, and $\mathrm{C}$ ) observed using tippingbucket rain gauges (Ogasawara Keiki Co. Ltd., RS-102) set at approximately $1 \mathrm{~m}$ height above the forest floor and rainfall collected at the road weather station at 3 $\mathrm{m}$ height above the ground surface were used for calculating fog deposition flux. As shown in Fig. 1 in the companion paper (Yamaguchi et al., 2013), all plots are located under the trees near the edge of the woodland and have little upwind fetch. The reason we have chosen such a location is that the study area is ecologically protected of nature. As a result, the possible difference in throughfall amounts is expected among three plots as discussed in subsection 3.2. The fog deposition flux was simply determined as the difference between throughfall and rainfall by neglecting the evaporation 


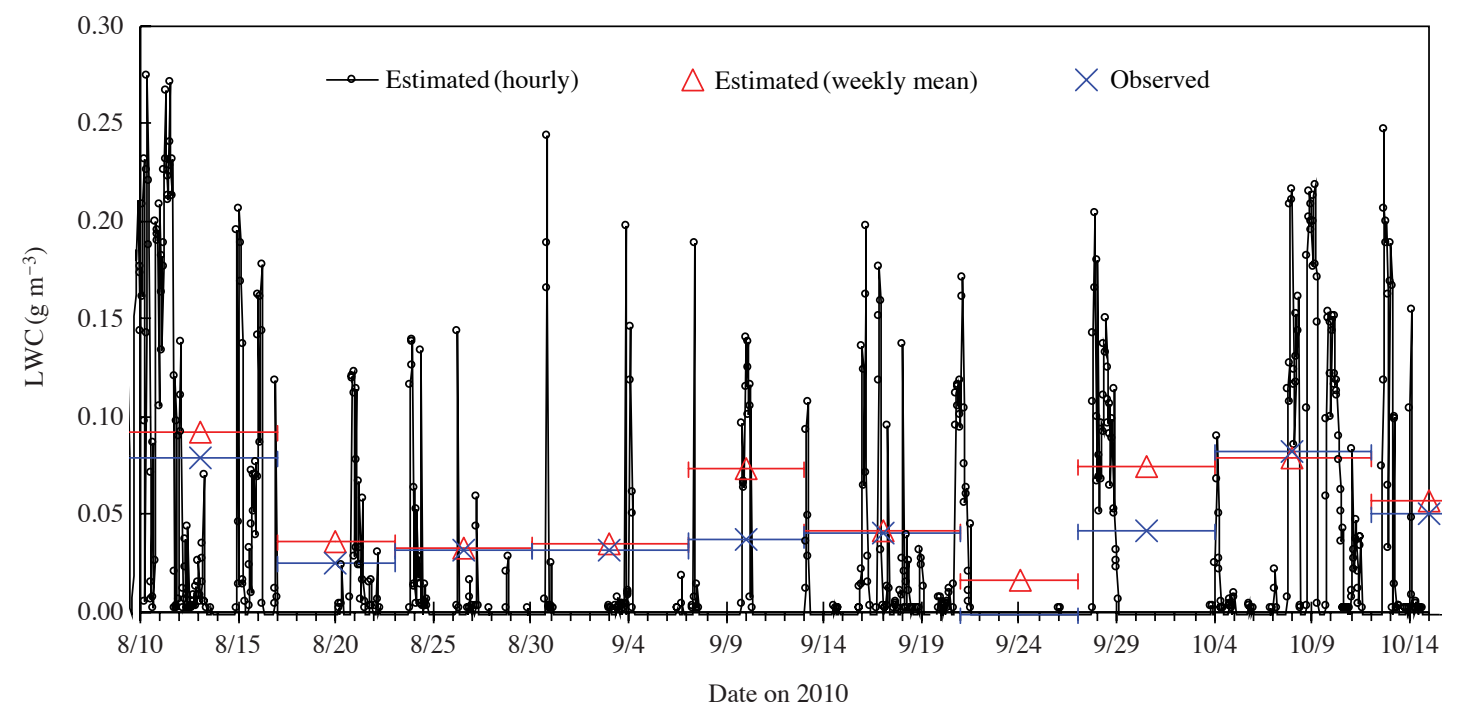

Fig. 2. Temporal changes in observed (blue crosses) and estimated (open circles and red triangles) liquid water content of fog (LWC) from 10 August to 15 October 2010.

loss from intercepted fog or rain water at the wetted canopy (Yamaguchi et al., 2013, companion paper). Canopy height and LAI observed using a VERTEX IV hypsometer (Haglof Co., Sweden) and LAI-2000 plant canopy analyzer (LI-COR Co., USA), respectively, were used for Eqs.(4) and (5). Measured values of canopy height and LAI on 10 August 2010 were approximately $10 \mathrm{~m}$ and $1.5 \pm 0.16$, respectively. Details of the site description and sampling method for weekly LWC and throughfall are provided in the companion paper (Yamaguchi et al., 2013).

\section{RESULTS AND DISCUSSION}

\section{1 Estimation of Liquid Water Content of Fog}

Fig. 2 shows the time series of observed and estimated LWC from 10 August to 15 October 2010. The highest values of weekly LWC were found during the periods from 9 to 17 on August and 4 to 12 October, while fog was not observed from 21 to 27 September. A similar pattern of weekly LWC averaged from hourly LWC was also found in the estimation results except for slight overestimations on 9 and 29 September. Fig. 3 shows comparisons between observations and estimations of weekly LWC. A good correlation between estimations and observations was found $\left(R^{2}=0.734\right)$. Average error and root-mean-square error (RMSE) of weekly LWC between the estimations and observations are 0.051 and $0.018 \mathrm{~g} \mathrm{~m}^{-3}$, respectively, which are small compared with the mean value of estimated weekly LWC $\left(0.094 \mathrm{~g} \mathrm{~m}^{-3}\right)$. These results indicate that the empirical relationship between VIS and LWC is

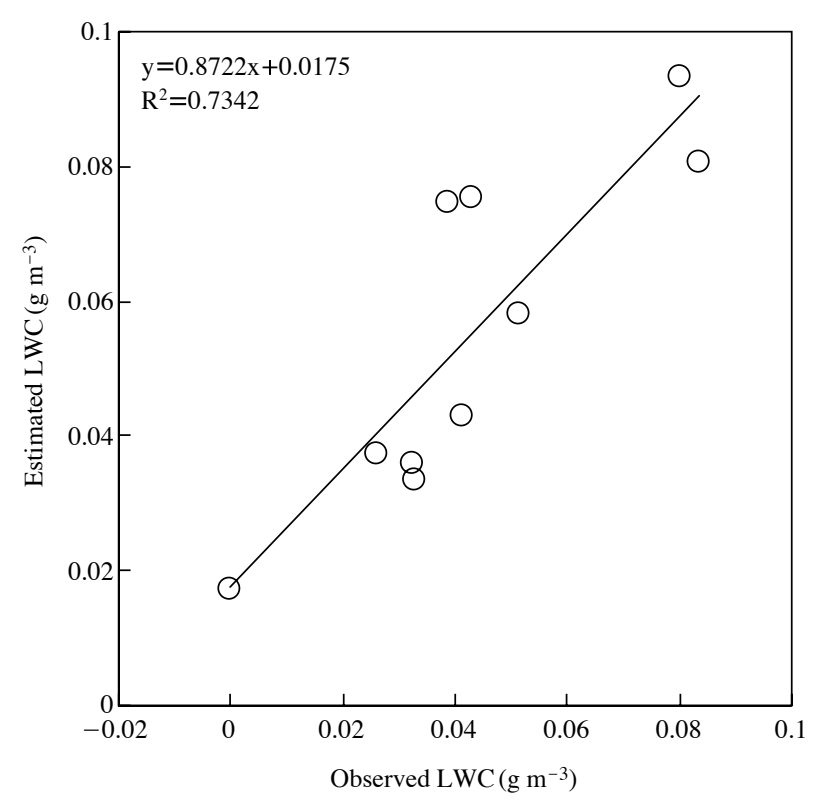

Fig. 3. Comparisons of estimated and calculated weekly averaged liquid water content of fog (LWC) from 10 August to 15 October 2010.

useful in prediction of LWC in the study area.

\section{2 Estimation of Fog Deposition in Cool-Temperate Deciduous Forest}

Fig. 4 shows the temporal changes in observed rainfall and throughfall and estimated fog deposition in the calculation period. From 9 to 10 and 27 to 29 September, fog deposition is considered to be overestimat- 

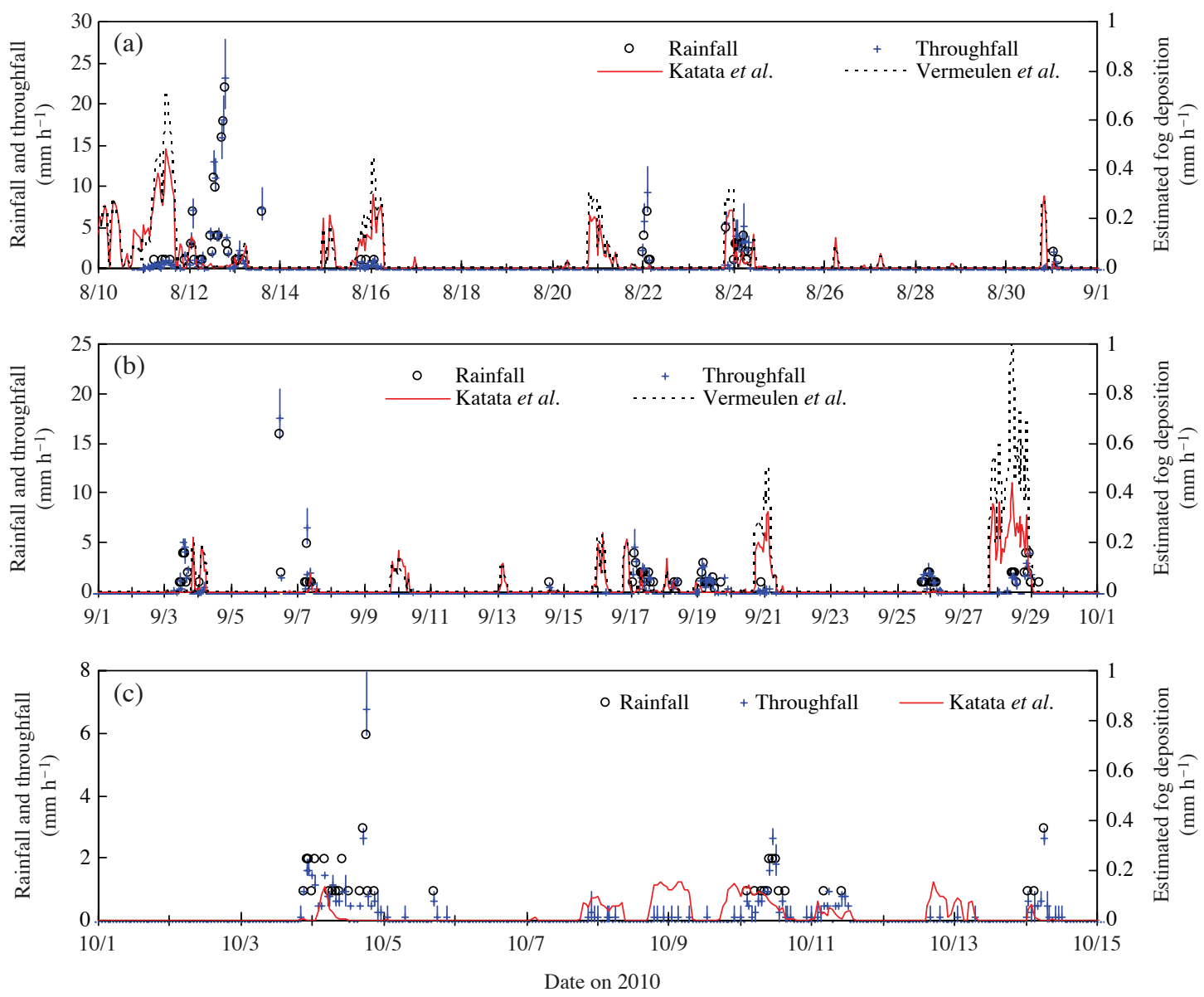

Fig. 4. Temporal changes in estimated fog deposition (solid and dashed lines) and observed rainfall (open circles) and mean throughfall under three tree stands (crosses) at Lake Mashu (a) from 10 to 31 August, (b) from 1 to 30 September, and (c) from 1 to 15 October 2010. Vertical bars with crosses show the range of maximum and minimum values among three tree stands.

ed due to overestimations of LWC calculated from VIS (Fig. 2). In other periods in August and September, however, fog deposition was also often overestimated when no throughfall event was observed. This phenomenon may be explained by the evaporation loss of rain and fog droplets intercepted by tree canopies as discussed in subsection 3.3. As shown in Fig. 4, many throughfall events accompanied rainfall in observations. Under rain-free conditions, there was one event of fog deposition from 7 to 9 October (Fig. 5). During this period, fog occurrence and deposition were well predicted by the parameterization of Katata et al. (2008). This indicates that the inferential method using the parameterizations of deposition velocity and LWC reasonably predicts fog deposition under rain-free conditions.

Table 1 summarizes meteorological variables and cumulative fog deposition from 10 August to 15 October 2010. For calculations of cumulative fog deposi-

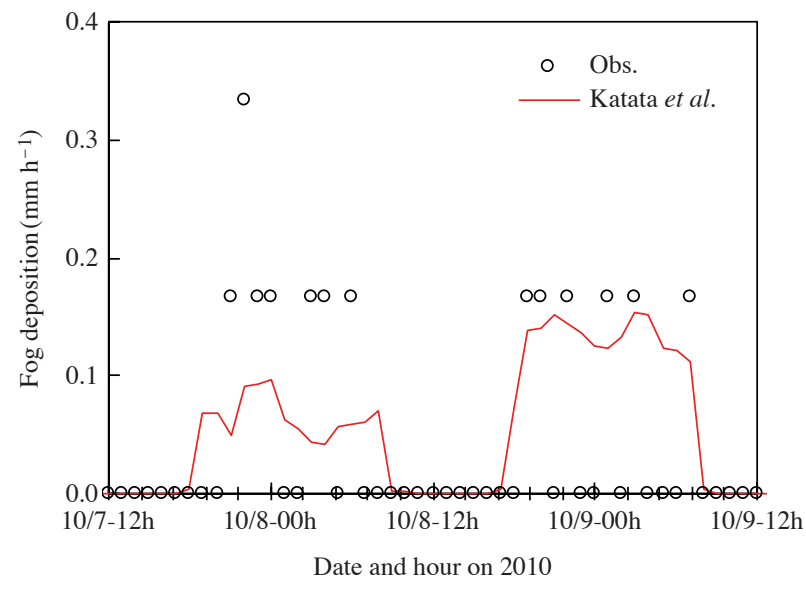

Fig. 5. Temporal changes in estimated (solid lines) and measured fog deposition (open circles) under rain-free conditions from 7 to 9 October 2010. Observations represent the averaged values of fog deposition for three tree stands (plots A, B, and C). 
Table 1. Summary of averaged wind speed at $20 \mathrm{~m}$ in height $\left(U_{z}\right)$ and liquid water content of fog (LWC), and cumulative fog deposition from 10 August to 15 October 2010. Values in parentheses show the accumulated fog deposition amount independent of throughfall events.

\begin{tabular}{|c|c|c|c|c|c|c|c|c|}
\hline \multirow{2}{*}{ Periods } & \multirow{2}{*}{$\begin{array}{c}U_{z} \\
\left(\mathrm{~m} \mathrm{~s}^{-1}\right)\end{array}$} & \multirow{2}{*}{$\begin{array}{c}\mathrm{LWC} \\
\left(\mathrm{g} \mathrm{m}^{-3}\right)\end{array}$} & \multicolumn{4}{|c|}{ Observed fog deposition (mm) } & \multicolumn{2}{|c|}{ Calculated fog deposition (mm) } \\
\hline & & & Plot A & Plot B & Plot C & Mean & Katata et al.(2008) & Vermeulen et al.(1997) \\
\hline 10-31 Aug. & 6.0 & 0.064 & 20.5 & 5.0 & 55.5 & 27.0 & $9.4(22.6)$ & $11.0(23.7)$ \\
\hline 1-30 Sep. & 7.6 & 0.052 & 8.0 & 0.5 & 11.5 & 8.5 & $5.1(14.9)$ & $8.5(22.1)$ \\
\hline 1-15 Oct. & 4.7 & 0.073 & 7.5 & 4.5 & 4.5 & 5.5 & $4.0(7.1)$ & - \\
\hline All periods & 6.1 & 0.063 & 36.5 & 10.0 & 71.0 & 39.2 & $18.5(44.5)$ & - \\
\hline
\end{tabular}

tion amount, throughfall events are considered when fog sensors of an active string-fog collector were activated. The throughfall data varied considerably at plots $\mathrm{A}, \mathrm{B}$, and $\mathrm{C}$ in all months. This is considered to be due to sampling errors in the throughfall measurements caused by spatial variation in amounts of intercepted rainfall (Holwerda et al., 2006); i.e., when rainfall occurred, additional spatial variation in throughfall may have resulted from differential interception of inclined rainfall by the canopy surface and redistribution of intercepted rain within the canopy (Herwitz and Slye, 1992; Lloyd and Marques, 1988). The amounts of fog deposition estimated by the parameterizations were small, approximately a half or third of observations in all months (Table 1). This is similar to the comparisons of fog deposition in a mountainous coniferous forest in Japan (Katata et al., 2011). As suggested by Katata et al. (2011), the underestimation is probably due to enhancement of fog deposition by the "edge effect" which causes considerable increase in fog deposition compared to that inside the forest stand due to inflow and advection processes (e.g., Hasselrot and Grennfelt, 1987). In the study area, it is expected that the edge effect might be large when the wind flows from the west of plots $\mathrm{A}, \mathrm{B}$, and $\mathrm{C}$ along grassland areas without trees (Yamaguchi et al., 2013, companion paper). The largest values in throughfall data among three plots (Table 1) may reflect the fact that plot $C$ is closer to the edge than plots A and B. When fog appeared, the frequencies of observed westerly wind were $50-60 \%$ per a month in all three months (not shown). Thus, by considering the enhancement of fog deposition due to the edge effect for the whole calculation period in similarity with Katata et al. (2010), the current parameterization can reasonably simulate fog deposition events.

\section{3 Limitations of the Current Parameteriza- tions}

By comparing fog deposition amounts estimated by two parameterizations (Table 1), the parameterization of Vermeulen et al. (1997) produced a larger value than that of Katata et al. (2008) in August and September
2010. This is due to the difference in expressions of deposition velocity in terms of momentum transfer $\left(U_{z}\right.$ or $\left.u^{*}\right)$ in the parameterizations. As described in subsection 2.1, under windy conditions, Eq.(3) produces a large deposition velocity compared with Eq.(5) (Fig. 1). In fact, averaged wind speed at $20 \mathrm{~m}$ height $\left(U_{z}\right)$ was estimated to be as large as 6.0 and $7.6 \mathrm{~m} \mathrm{~s}^{-1}$ in August and September, respectively (Table 1). In such situations, however, fog deposition may be overestimated because the observed wind speed was beyond the range of availability of Eq.(3), i.e., $U_{z}<3 \mathrm{~m} \mathrm{~s}^{-1}$. Unfortunately, it is difficult to validate the parameterization of Vermeulen et al. (1997) under the strong wind speed by comparing with the throughfall data in the present study because the data varied very large among three plots (Table 1). It is necessary to validate the parameterization of Vermeulen et al. (1997) with more observational data collected over the areas with a sufficient upwind fetch under windy conditions.

As shown in subsection 3.2, the current parameterizations computed the fog deposition even when throughfall was not observed because evaporation loss of rain or fog droplets intercepted by tree canopies was not considered (Fig. 4). Although the effect of evaporation loss is not considered to be particularly large in such situations as the fog episode continued without a long fog-free period (Kobayashi et al., 1999), error associated with evaporation loss probably accumulated while estimating fog deposition (e.g., Bruijnzeel $e t$ al., 2011). Moreover, when throughfall events were not detected, fog was less dense (hourly LWC $<0.1 \mathrm{~g} \mathrm{~m}^{-3}$, Fig. 2) and appeared from midnight to the early morning in most cases. This indicates that intercepted rain or fog water can easily evaporate with an increase of ambient temperature during the morning. If estimated fog deposition flux was accumulated independent of the throughfall events, then the total amount of estimated fog deposition in the calculation period would be increased by approximately $60 \%$ (Table 1 ). Consequently, the effect of evaporation loss on fog deposition cannot be neglected for accurate prediction of the amount of fog deposition using the current parameterizations. 
Although the parameterization of Eq.(5) underestimated monthly cumulative fog deposition (Table 1), the observed fog deposition under rain-free condition is well predicted (Fig. 5). This discrepancy can be explained by the effects of tree physiology by indicating a decrease of LAI of deciduous forest due to defoliation. In the study area, leaves fell onto the ground surface during the period from the end of September to the beginning of October 2010 (Yamaguchi et al., 2013, companion paper). The effect of defoliation is not considered in the present estimation due to the lack of LAI data for September and October, which can cause overestimations of fog deposition during the fall season. The parameterization of Eq.(5) has not yet been tested with data collected in tree canopies with low leaf areas because many cloud forests in the world have a large LAI (Katata et al., 2008). More investigation of seasonal changes in fog deposition with LAI of deciduous forests is required for further discussion.

\section{CONCLUSIONS}

Prediction accuracy of fog deposition onto a cooltemperate deciduous forest in northern Japan was investigated using the available parameterizations. The hourly liquid water content of fog (LWC) was estimated using the empirical function of horizontal visibility (VIS). By using the estimated values of LWC, fog deposition was calculated using the inferential method through parameterizations of deposition velocity for European forests. A good correlation between estimations of LWC using the parameterizations and observations of LWC through an active string-fog collector was found on a weekly basis. By considering the enhancement of fog deposition due to the edge effect, the inferential method reasonably predicted fog deposition calculated from rainfall and throughfall data. When high wind speed was observed, the use of the parameterization of Katata et al. (2008) may be preferred for a reasonable estimation of fog deposition compared with that of Vermeulen et al. (1997). The effect of evaporation loss on fog deposition cannot be neglected for accurate prediction of fog deposition by the inferential method. More investigation of seasonal changes in fog deposition with LAI of deciduous forests is required.

\section{ACKNOWLEDGEMENT}

The present study was partially supported by a Grantin-Aid for Scientific Research on Innovative Areas (21 120512, 23120701) and for Young Scientists B (2171
0035) from the Ministry of Education, Culture, Sports, Science and Technology.

\section{REFERENCES}

Aikawa, M., Hiraki, T., Shoga, M., Tamaki, M., Sumitomo, S. (2007) Seven-year trend and the time and seasonal dependence of fog water collected near an industrialized area in Japan. Atmospheric Research 83, 1-9.

Beswick, K.M., Hargreaves, K.J., Gallagher, M.W., Choularton, T.W., Fowler, D. (1991) Size-resolved measurements of cloud droplet deposition velocity to a forest canopy using an eddy correlation technique. Quarterly Journal Royal Meteorological Society 117, 623-645.

Bruijnzeel, L.A., Mulligan, M., Scatena, F.N. (2011) Hydrometeorology of tropical montane cloud forests: emerging patterns. Hydrological Processes 25, 465-498.

Erisman, J.W., Pul, A.V., Wyers, P. (1994) Parametrization of surface resistance for the quantification of atmospheric deposition of acidifying pollutants and ozone. Atmospheric Environment 28, 2595-2607.

Erisman, J.W., Draaijers, G.P.J. (1995) Atmospheric deposition in relation to acidification and eutrophication, Studies in Environmental Science, 63, Elsevier, Amsterdam.

Eugster, W., Burkard, R., Holwerda, F., Scatena, F.N., Bruijnzeel, L.A. (2006) Characteristics of fog and fogwater fluxes in a Puerto Rican elfin cloud forest. Agricultural and Forest Meteorology 139, 288-306.

Fowler, D., Morse, A.P., Gallagher, M.W., Choularton, T.W. (1990) Measurements of cloud water deposition on vegetation using a lysimeter and a flux gradient technique. Tellus 42B, 285-293.

Fujinuma, Y., Kawai, T., Atsuya, I., Tanaka, A., Hamada, H., Fukazawa, T., Sakata, K., Minami, N., Imada, K. (2004) Lake Mashu Monitoring databook in GEMS/Water program. In CGER-REPORT-M016-2004: GEMS/ Water Lake Mashu Monitoring Data Book (in Japanese).

Gultepe, I., Müller, M.D., Boybeyi, Z. (2006) A new visibility parameterization for warm-fog applications in numerical weather prediction models. Journal of Applied Meteorology and Climatology 45, 1469-1480.

Hasselrot, B., Grennfelt, P. (1987) Deposition of air pollutants in a wind-exposed forest edge. Water, Air, and Soil Pollution 34, 135-143.

Herckes, P., Wendling, R., Sauret, N., Mirabel, P., Wortham, H. (2002) Cloudwater studies at a high elevation site in the Vosges Mountains (France). Environmental Pollution 117, 169-177.

Herwitz, S.R., Slye, R.E. (1995) Three-dimensional modeling of canopy tree interception of wind-driven rainfall. Journal of Hydrology 168, 205-226.

Hicks, B.B., Baldocchi, D.D., Meyers, T.P., Hosker, R.P., Matt, D.R. (1987) A preliminary multiple resistance routine for deriving dry deposition velocities from measured quantities. Water, Air, and Soil Pollution 36, 311330. 
Holwerda, F., Burkard, R., Eugster, W., Scatena, F.N., Meesters, A.G.C.A., Bruijnzeel, L.A. (2006) Estimating fog deposition at a Puerto Rican elfin cloud forest site: Comparison of the water budget and eddy covariance methods. Hydrological Processes 20, 2669-2692.

Igawa, M., Matsumura, K., Okochi, H. (2002) High frequency and large deposition of acid fog on high elevation forest. Environmental Science and Technology 36, 1-6.

Katata, G., Nagai, H., Wrzesinsky, T., Klemm, O., Eugster, W., Burkard, R. (2008) Development of a land surface model including cloud water deposition on vegetation. Journal of Applied Meteorology and Climatology 47, 2129-2146.

Katata, G., Kajino, M., Hiraki, T., Aikawa, M., Kobayashi, T., Nagai, H. (2011) A method for simple and accurate estimation of fog deposition in a mountain forest using a meteorological model. Journal of Geophysical Research 116, D20102.

Klemm, O., Wrzesinsky, T., Scheer, C. (2005) Fog water flux at a canopy top: Direct measurement versus onedimensional model. Atmospheric Environment 39, 5375-5386.

Kobayashi, T., Nakagawa, Y., Tamaki, M., Hiraki, T., Aikawa, M., Shoga, M. (1999) Estimation of acid deposition to forest canopies via cloud water by means of through fall measurements and cloud water collectionMeasurements in Cryptomeria Japonica stands at Mt. Rokko. Environmental Science 12, 399-411 (in Japanese with English abstract, figures, and tables).

Kunkel, B.A. (1984) Parameterization of droplet terminal velocity and extinction coefficient in fog models. Journal of Applied Meteorology 23, 34-41.

Lange, C.A., Matschullat, J., Zimmermann, F., Sterzik, G., Wienhaus, O. (2003) Fog frequency and chemical composition of fog water-A relevant contribution to atmospheric deposition in the eastern Erzgebirge, Germany. Atmospheric Environment 37, 3731-3739.

Lloyd, C.R., Marques, A.D. (1988) Spatial variability of throughfall and stemflow measurements in Amazonian rain forest. Agricultural and Forest Meteorology 42, 6373.

Lovett, G.M. (1984) Rates and mechanisms of cloud water deposition to a subalpine balsam fir forest. Atmospheric Environment 18, 361-371.

Matsuda, K., Watanabe, I., Wingpud, V., Theramongkol,
P., Ohizumi, T. (2006) Deposition velocity of $\mathrm{O}_{3}$ and $\mathrm{SO}_{2}$ in the dry and wet season above a tropical forest in northern Thailand. Atmospheric Environment 40, 75577564.

Mueller, S.F., Joslin Jr., J.D., Wolfe, M.H. (1991) Estimating cloud water deposition to subalpine spruce-fir forests II. Model testing. Atmospheric Environment 25A, 1105-1122.

Seinfeld, J.H., Pandis, S.N. (2006) Atmospheric Chemistry and Physics-From Air Pollution to Climate Change (2nd Ed.), Wiley-Interscience, New York.

Stoelinga, M.T., Warner, T.T. (1999) Nonhydrostatic, mesobeta-scale model simulations of cloud ceiling and visibility for an east coast winter precipitation event. Journal of Applied Meteorology 38, 385-404.

Tago, H., Kimura, H., Kozawa, K., Fujie, K. (2006) Longterm observation of fogwater composition at two mountainous sites in Gunma Prefecture, Japan. Water, Air and Soil Pollution 175, 375-391.

Vermeulen, A.T., Wyers, G.P., Römer, F.G., Van Leeuwen, N.F.M., Draaijers, G.P.J., Erisman, J.W. (1997) Fog deposition on a coniferous forest in the Netherlands. Atmospheric Environment 31, 375-386.

Watanabe, K., Honoki, H., Iwai, A., Tomatsu, A., Noritake, K., Miyashita, N., Yamada, K., Yamada, H., Kawamura, H., Aoki, K. (2010) Chemical characteristics of fog water at Mt. Tateyama, near the coast of the Japan Sea in central Japan. Water, Air, and Soil Pollution 211, 379-393.

Wesely, M.L. (1989) Parameterization of surface resistances to gaseous dry deposition in regional-scale numerical models. Atmospheric Environment 23, 1293-1304.

Yamaguchi, T., Noguchi, I., Watanabe, Y., Katata, G., Sato, H., Hara, H. (2013) Aerosol deposition and behavior on leaves in cool-temperate deciduous forests. Part 2. Characteristics fogwater chemistry at Lake Mashu, northern Japan in 2010. Asian Journal of Atmospheric Environment, this issue.

Zhang, L., Gong, S., Padro, J., Barrie, L. (2001) A sizesegregated particle dry deposition scheme for an atmospheric aerosol module. Atmospheric Environment 35, 549-560.

(Received 31 May 2012, revised 11 September 2012, accepted 21 September 2012) 